\title{
HERANÇA DA TOLERÂNCIA AO ALUMÍNIO EM POPULAÇÕES HÍBRIDAS DE TRIGO'
}

\author{
CARLOS EDUARDO DE OLIVEIRA CAMARGO², ANTONIO WILSON PENTEADO FERREIRA FILHO² \\ e JOÃO CARLOS FELICIO ${ }^{3}$
}

\begin{abstract}
RESUMO - Plântulas originárias de populações híbridas, em geração $\mathrm{F}_{2}$, de 26 cruzamentos entre cultivares de trigo tolerantes (BH-1146, IAC-227, IAC-24, IAC-60, C-3, IAC-5, IAC-18 e IAC-21) e sensíveis (Anahuac 75, IAC-287, IAC-289, Siete Cerros e Veery “S”) à toxicidade de alumínio e de 18 cruzamentos entre cultivares tolerantes (BH-1146, IAC-227, IAC-24, IAC-60, C-3, IAC-5, IAC-21, C-17, IAC-74 e IAC-18) foram avaliadas em relação à tolerância a $3 \mathrm{mg} / \mathrm{L}$ de $\mathrm{Al}^{3+}$, empregando soluções nutritivas. A tolerância à toxicidade de alumínio foi medida pela capacidade de crescimento da raiz primária central em solução nutritiva completa, após um tratamento de 48 horas em solução contendo $3 \mathrm{mg} / \mathrm{L}$ de $\mathrm{Al}^{3+}$. Avaliando-se as plântulas das populações $\mathrm{F}_{2}$ provindas de cruzamentos entre cultivares tolerantes e sensíveis, verificou-se que a tolerância à toxicidade de $\mathrm{Al}^{3+}$ foi dominante, e que em 24 dos cruzamentos, as cultivares tolerantes diferiram das sensíveis por um par de genes. Não foi detectada diferença entre as cultivares tolerantes em relação ao par de genes dominantes em relação à tolerância. Qualquer uma dessas cultivares poderá ser utilizada como fonte de tolerância num programa de cruzamentos em que essa característica for desejada.
\end{abstract}

Termos para indexação: Triticum aestivum, toxicidade de alumínio, cultivares tolerantes, cultivares sensíveis, genes dominantes, solução nutritiva.

\section{INHERITANCE OF ALUMINUM TOLERANCE IN WHEAT HYBRID POPULATIONS}

\begin{abstract}
Seedlings originated from hybrid populations, in $\mathrm{F}_{2}$ generation, from 26 crosses between tolerant wheat cultivars (BH-1146, IAC-227, IAC-24, IAC-60, C-3, IAC-5, IAC-18 and IAC-21) and sensitive cultivars (Anahuac 75, IAC-287, IAC-289, Siete Cerros and Veery "S") to aluminum toxicity and from 18 crosses between tolerant cultivars (BH-1146, IAC-227, IAC-24, IAC-60, C-3, IAC-5, IAC-21, C-17, IAC-74 and IAC-18) were evaluated for tolerance to $3 \mathrm{mg} / \mathrm{L}$ of $\mathrm{Al}^{3+}$, using nutrient solutions. It was considered tolerant the plant that was able to show root regrowth of the central primary root in the complete nutrient solution after a treatment of 48 hours in solution containing $3 \mathrm{mg} / \mathrm{L}$ of $\mathrm{Al}^{3+}$. The evaluation of the seedlings from the $\mathrm{F}_{2}$ populations originated from the tolerant and sensitive crosses showed that the tolerance to $\mathrm{Al}^{3+}$ toxicity was dominant and in 24 of the crosses the tolerant cultivars differed from the sensitive by one pair of genes. No difference was observed between the tolerant cultivars in relation to the pair of genes for the tolerance. Each one of these cultivars could be used as tolerance source in a crossing program, where this trait would be desired.
\end{abstract}

Index terms: Triticum aestivum, aluminum toxicity, tolerant cultivars, sensitive cultivars, dominant pair of genes, nutrient solution.

${ }^{1}$ Aceito para publicação em 10 de maio de 1999.

${ }^{2}$ Eng. Agrôn., Dr., Instituto Agronômico (IAC), Caixa Postal 28, CEP 13001-970 Campinas, SP. Bolsista do CNPq. E-mail: ccamargo@cec.iac.br

${ }^{3}$ Eng. Agrôn., IAC.

\section{INTRODUÇÃO}

A toxicidade devida ao $\mathrm{Al}$ reduz a produção de trigo em muitas terras agricultáveis, além de limitar a expansão da área mundial cultivada com esse 
cereal principalmente em solos ácidos. A maioria das cultivares tolerantes originou-se por seleção em solos onde esse elemento é encontrado naturalmente em níveis que causam toxicidade às plantas sensíveis.

Kerridge (1969) concluiu que o efeito primário da toxicidade de $\mathrm{Al}$ no trigo é a paralisação do crescimento da raiz, e Moore et al. (1976) informaram que é muito difícil controlar adequadamente o complexo mineral do solo para que determinado nível de $\mathrm{Al}$ possa ser reproduzido de um experimento para outro ou de um local para outro. Além do mais, essa toxicidade não é o único fator limitante em solos ácidos, e, portanto, os métodos de separação de plantas tolerantes e sensíveis em determinado nível de Al, usando solos ácidos não são bastante precisos. Outro problema é que as partes da planta diretamente afetadas, as raízes, não são facilmente observáveis. O emprego de soluções nutritivas pode tornar mais eficiente e precisa a separação das plantas em relação à tolerância ao Al.

Um método rápido para a identificação de plantas tolerantes e de fácil reprodução foi desenvolvido na Universidade de Oregon, com base na paralisação irreversível do meristema das raízes primárias do trigo no estádio de plântula, utilizando-se soluções nutritivas contendo diferentes níveis de $\mathrm{Al}^{3+}$. Este método permitiu classificar as cultivares $\mathrm{BH}-1146$, C-3, IAC-5, IAC-18, IAC-21, IAC-24, IAC-74, IAC-227, IAC-60 e C-17 como tolerantes, e as cultivares Anahuac 75, Siete Cerros, IAC-289 e IAC-287, como sensíveis (Camargo \& Oliveira, 1981; Felicio et al., 1991, 1994; Camargo, 1993; Camargo et al., 1996).

Estudos genéticos demonstraram que a tolerância à toxicidade de $\mathrm{Al}$ em trigo é governada por um ou dois pares de genes dominantes (Kerridge \& Kronstad, 1968; Camargo, 1981, 1984; Campbell \& Lafever, 1981).

Os resultados obtidos por Camargo (1984) avaliando populações de trigo oriundas do cruzamento de uma cultivar tolerante, e uma sensível em três concentrações de $\mathrm{Al}^{3+}$, empregando soluções nutritivas, mostraram haver genes ou blocos de genes que teriam um comportamento de dominância em concentrações mais baixas, dominância esta que seria quebrada à medida que a concentração de $\mathrm{Al}^{3+}$ fosse aumentada. Resultados semelhantes foram obtidos por Aniol (1984) e Bona et al. (1994), permitindo concluir que a expressão genética da tolerância ao Al é também influenciada pela severidade do estresse de Al.

O presente trabalho visou determinar o tipo de ação gênica envolvida na expressão da tolerância à toxicidade de $\mathrm{Al}$, em solução nutritiva, por populações híbridas de trigo provindas de cruzamentos entre genótipos tolerantes e entre genótipos tolerantes e sensíveis.

\section{MATERIAL E MÉTODOS}

As sementes híbridas em geração $F_{2}$ de 26 cruzamentos entre cultivares de trigo tolerantes e sensíveis à toxicidade de $\mathrm{Al}$ e de 18 cruzamentos entre cultivares tolerantes foram obtidas a partir da semeadura da geração $F_{1}$ em vasos no telado contra o ataque de pássaros, localizado no Núcleo Experimental de Campinas. A genealogia e o tipo de reação à toxicidade de $\mathrm{Al}$ das cultivares empregadas nas hibridações encontram-se relacionadas na Tabela 1.

Foram consideradas como tolerantes as cultivares que apresentaram crescimento da raiz após um período de 48 horas em solução nutritiva contendo $10 \mathrm{mg} / \mathrm{L}$ de $\mathrm{Al}^{3+}$, e sensíveis, as cultivares que mostraram paralisação de crescimento da raiz após um período de 48 horas em solução nutritiva contendo $2 \mathrm{mg} / \mathrm{L}$ de $\mathrm{Al}^{3+}$ (Camargo et al., 1996).

As 26 populações híbridas oriundas de cruzamentos entre as cultivares tolerantes BH-1146, IAC-227, IAC-24, IAC-60, C-3, IAC-5, IAC-18 e IAC-21 e as sensíveis Anahuac 75, Siete Cerros, IAC-287, IAC-289 e Veery "S", foram testadas quanto à tolerância a $3 \mathrm{mg} / \mathrm{L}$ de $\mathrm{Al}^{3+}$, no experimento I, no qual empregou-se a técnica citada por Camargo (1981) e descrita a seguir:

As sementes de 26 populações híbridas e dos parentais foram cuidadosamente lavadas com uma solução de hipoclorito de sódio a $10 \%$ e colocadas para germinar em placas de Petri por 72 horas, em refrigerador com temperatura de $12^{\circ} \mathrm{C}$. Após esse tempo as radículas estavam iniciando a emergência.

As sementes uniformes dessas populações híbridas foram colocadas com auxílio de uma pinça sobre o topo de 13 telas de nylon, de modo que cada tela contivesse sementes (no mínimo 93) de duas populações híbridas e cinco sementes de cada parental envolvido. As telas de nylon foram adaptadas sobre vasilhas de plástico, de 8,3 litros de capacidade, contendo soluções nutritivas completas, de maneira que as sementes fossem mantidas 
úmidas e as radículas emergentes tocassem nas soluções, tendo, portanto, um pronto suprimento de água e nutrientes.

A concentração da solução nutritiva completa utilizada, proposta por Moore et al. (1976), foi a seguinte: $\mathrm{Ca}\left(\mathrm{N} \mathrm{O}_{3}\right)_{2} 4 \mathrm{mM} ; \mathrm{Mg} \mathrm{SO}_{4} 2 \mathrm{mM} ; \mathrm{K} \mathrm{N} \mathrm{O}_{3} 4 \mathrm{mM}$; $\left(\mathrm{NH}_{4}\right)_{2} \mathrm{SO}_{4} 0,435 \mathrm{mM} ; \mathrm{KH}_{2} \mathrm{PO}_{4} 0,5 \mathrm{mM} ; \mathrm{MnSO}_{4} 2 \mu \mathrm{M}$; $\mathrm{CuSO}_{4} 0,3 \mu \mathrm{M} ; \mathrm{ZnSO}_{4} 0,8 \mu \mathrm{M} ; \mathrm{NaCl} 30 \mu \mathrm{M}$; Fe-CYDTA $10 \mu \mathrm{M} ; \mathrm{Na}_{2} \mathrm{MoO}_{4} 0,10 \mu \mathrm{M}$ e $\mathrm{H}_{3} \mathrm{BO}_{3} 10 \mu \mathrm{M}$. $\mathrm{O}$ pH da solução foi previamente ajustado para 4,0 com $\mathrm{H}_{2} \mathrm{SO}_{4} 1 \mathrm{~N}$. A solução foi continuamente arejada, e as 13 vasilhas de plástico contendo as soluções foram colocadas em banho-maria com temperatura de $25 \pm 1^{\circ} \mathrm{C}$ dentro do laboratório.

As plântulas desenvolveram-se nesse ambiente por um período de 48 horas. Após esse tempo, cada plântula tinha três raízes primárias, sendo uma mais longa, medindo cerca de $4,5 \mathrm{~cm}$ e duas mais curtas, localizadas lateralmente à primeira.

Cada uma das telas de nylon contendo as plântulas das populações estudadas foi transferida para outra vasilha de plástico contendo soluções de tratamento com $3 \mathrm{mg} / \mathrm{L}$ de $\mathrm{Al}$ na forma de $\mathrm{Al}_{2}\left(\mathrm{SO}_{4}\right)_{3} \cdot 18 \mathrm{H}_{2} \mathrm{O}$.

A composição da solução de tratamento foi de um décimo da solução completa, excetuando-se o $\mathrm{P}$, que foi omitido, e o $\mathrm{Fe}$, que foi adicionado em quantidade equivalente, com $\mathrm{F}_{2} \mathrm{Cl}_{3}$ no lugar de $\mathrm{Fe}-\mathrm{CYDTA}$, como foi descrito por Moore et al. (1976). O P foi omitido, para evitar a possível precipitação do Al. Devido à possibilida- de da precipitação do $\mathrm{Al}$ como $\mathrm{Al}(\mathrm{OH})_{3}$, especial atenção foi dada a esse ponto. Antes de transferir as telas para as soluções de tratamento, suficiente volume de $\mathrm{H}_{2} \mathrm{SO}_{4} 1 \mathrm{~N}$ foi adicionado para estabelecer o $\mathrm{pH}$ em torno de 4,2, e então, foi colocada a necessária quantidade de $\mathrm{Al}$, como $\mathrm{Al}_{2}\left(\mathrm{SO}_{4}\right)_{3} \cdot 18 \mathrm{H}_{2} \mathrm{O}$. O pH final foi ajustado para $4,0 \mathrm{com}$ $\mathrm{H}_{2} \mathrm{SO}_{4} 1 \mathrm{~N}$, evitando-se adicionar $\mathrm{NaOH}$, que poderia causar a precipitação do $\mathrm{Al}$, pelo menos no local de queda da gota.

As plântulas permaneceram crescendo por 48 horas nas soluções de tratamento em banho-maria, com temperatura de $25 \pm 1^{\circ} \mathrm{C}$. Após este período, as telas contendo as plântulas foram transferidas novamente para as vasilhas de plástico contendo as soluções nutritivas completas onde haviam crescido no início do experimento. Nessas condições permaneceram por mais 72 horas, com temperatura de $25 \pm 1^{\circ} \mathrm{C}$. O crescimento das raízes primárias das plântulas nestas 72 horas depende do nível de tolerância à toxicidade de $\mathrm{Al}$ e as sensíveis não crescem mais e permanecem grossas, mostrando no ápice uma lesão típica com descoloramento (Moore et al., 1976). Determinou-se a quantidade de crescimento da raiz de cada plântula medindo-se o comprimento da raiz primária central após as 72 horas de imersão na solução nutritiva completa, subtraindo-se do comprimento da mesma raiz, no final do crescimento na solução de tratamento.

Durante todo o experimento, manteve-se o $\mathrm{pH}$ das soluções o mais próximo possível de 4,0, por ajustamen-

TABELA 1. Genealogia e tipo de reação à toxicidade de alumínio ${ }^{1}$ dos genótipos de trigo utilizados nos cruzamentos.

\begin{tabular}{|c|c|c|}
\hline Genótipo & Genealogia & Toxicidade de $\mathrm{Al}^{3+}$ \\
\hline Anahuac 75 & II 12300//Lerma Rojo 65/8156/3/Norteño 67 & S \\
\hline BH-1146 & PG $1 / /$ Fronteira/Mentana & $\mathrm{T}$ \\
\hline C-3 - Cotiporã & Veranopolis $* 2 /$ Egypt NA 101 & $\mathrm{~T}$ \\
\hline C-17 - Lagoa Vermelha & Veranopolis *2//Marroqui/Newthatch & $\mathrm{T}$ \\
\hline IAC-5 - Maringá & Frontana/Kenya 58//PG 1 & $\mathrm{~T}$ \\
\hline IAC-18 - Xavantes & BH-1146*4/S 12 & $\mathrm{~T}$ \\
\hline IAC-21 - Iguaçú & Siete Cerros/C-17 & $\mathrm{T}$ \\
\hline IAC-24 - Tucuruí & IAS 51/IRN 597-70 & $\mathrm{T}$ \\
\hline IAC-60 - Centenário & IRN 33-70/IAC-5 & $\mathrm{T}$ \\
\hline IAC-74 - Guaporé & Sonora $63 * 2 / \mathrm{C}-17$ & $\mathrm{~T}$ \\
\hline IAC-227 - Anhumas & CNT 9/BH-1146 & $\mathrm{T}$ \\
\hline IAC-287 - Yaco & Heima/Cocoraque 75//Nacozari 76 & S \\
\hline IAC-289 - Marruá & Kavkaz/Buho“S"//Kalyan/Bluebird & $S$ \\
\hline Siete Cerros & Penjamo “ S "/Gabo 55 & S \\
\hline Veery "S" & Kavkaz/Buho“S"//Kalyan/Bluebird & $S$ \\
\hline
\end{tabular}

${ }^{1} \mathrm{~S}$ : sensível à presença de $2 \mathrm{mg} / \mathrm{L}$ de $\mathrm{Al}^{3+}$ nas soluções; T: tolerante à presença de $10 \mathrm{mg} / \mathrm{L}$ de $\mathrm{Al}^{3+}$ nas soluções. 
tos diários, com uma solução de $\mathrm{H}_{2} \mathrm{SO}_{4} 1 \mathrm{~N}$, e empregou-se luz fluorescente contínua e arejamento das soluções.

No experimento II foram testadas quanto à tolerância a $3 \mathrm{mg} / \mathrm{L}$ de $\mathrm{Al}^{3+}$ as 18 populações híbridas provenientes de cruzamentos entre as cultivares tolerantes: $\mathrm{BH}-1146$, IAC-227, IAC-24, IAC-60, C-3, IAC-5, IAC-21, C-17, IAC-74 e IAC-18. Foi empregada a mesma técnica descrita no experimento I.

Nos dois experimentos, as frequiências de plantas tolerantes e sensíveis foram computadas com base nas reações de tolerância (crescimento da raiz após um período de 48 horas em solução contendo $3 \mathrm{mg} / \mathrm{L} \mathrm{de} \mathrm{Al}^{3+}$ ) e sensibilidade (paralisação de crescimento da raiz nas mesmas condições). O teste de quiquadrado foi utilizado para comparar as freqüências obtidas e esperadas pela hipótese de segregação de um par de genes.

\section{RESULTADOS E DISCUSSÃO}

As populações $\mathrm{F}_{2}$ dos cruzamentos $\mathrm{BH}-1146 \mathrm{x}$ Anahuac 75, BH-1146 x IAC-287, IAC-287 x BH-1146, BH-1146 x Siete Cerros, Siete Cerros x BH-1146, e IAC-289 x BH-1146 segregaram na proporção esperada, 3:1, com valores de probabilidade de 0,98-0,95; 0,75-0,50; 0,90-0,75; 0,75-0,50; 0,50-0,25 e 0,75-0,50, respectivamente (Tabela 2). Tais resultados concordam com os obtidos por Camargo (1981, 1993), em que a cultivar BH-1146 carrega um par de genes dominantes para a tolerância à toxicidade de $\mathrm{Al}$.

Observaram-se segregações semelhantes quando foram avaliadas as demais populações $F_{2}$ envol-

TABELA 2. Reações à toxicidade de alumínio $(3 \mathrm{mg} / \mathrm{L})$ em soluções nutritivas de populações híbridas de trigo em geração $F_{2}$, provenientes de cruzamentos entre genótipos tolerantes e sensíveis, expressas em número de plantas tolerantes (T) e número de plantas sensíveis $(\mathrm{S})$ ao alumínio tóxico

\begin{tabular}{|c|c|c|c|c|c|c|}
\hline \multirow[t]{2}{*}{ Cruzamento } & \multirow{2}{*}{$\begin{array}{c}\text { Reação } \\
\text { dos } \\
\text { parentais }\end{array}$} & \multicolumn{2}{|c|}{ Número de plantas } & \multirow{2}{*}{$\begin{array}{c}\text { Proporção } \\
\text { esperada } \\
\text { T : S }\end{array}$} & \multirow[t]{2}{*}{$\chi^{2}$} & \multirow[t]{2}{*}{ Probabilidade $^{1}$} \\
\hline & & $\mathrm{T}$ & S & & & \\
\hline Anahuac 75/BH-1146 & $\mathrm{S} \times \mathrm{T}$ & 227 & 76 & $3: 1$ & 0,001 & $0,98-0,95$ \\
\hline BH-1146/IAC-287 & $\mathrm{T} \times \mathrm{S}$ & 153 & 47 & $3: 1$ & 0,24 & $0,75-0,50$ \\
\hline IAC-287/BH-1146 & $\mathrm{S} \times \mathrm{T}$ & 96 & 31 & $3: 1$ & 0,02 & $0,90-0,75$ \\
\hline BH-1146/Siete Cerros & $\mathrm{T} \times \mathrm{S}$ & 86 & 26 & $3: 1$ & 0,19 & $0,75-0,50$ \\
\hline Siete Cerros/BH-1146 & $\mathrm{S} \times \mathrm{T}$ & 98 & 28 & $3: 1$ & 0,52 & $0,50-0,25$ \\
\hline IAC-289/BH-1146 & $\mathrm{S} \times \mathrm{T}$ & 159 & 49 & $3: 1$ & 0,23 & $0,75-0,50$ \\
\hline IAC-227/Anahuac 75 & $\mathrm{~T} \times \mathrm{S}$ & 96 & 37 & $3: 1$ & 0,56 & $0,50-0,25$ \\
\hline Anahuac 75/IAC-227 & $\mathrm{S} \times \mathrm{T}$ & 92 & 37 & $3: 1$ & 0,93 & $0,50-0,25$ \\
\hline IAC-287/IAC-227 & $\mathrm{S} \times \mathrm{T}$ & 240 & 70 & $3: 1$ & 0,97 & $0,50-0,25$ \\
\hline Siete Cerros/IAC-227 & $\mathrm{S} \times \mathrm{T}$ & 88 & 33 & $3: 1$ & 0,33 & $0,75-0,50$ \\
\hline IAC-289/IAC-227 & $\mathrm{S} \times \mathrm{T}$ & 95 & 24 & $3: 1$ & 1,48 & $0,25-0,10$ \\
\hline Veery “S "/IAC-227 & $\mathrm{S} \times \mathrm{T}$ & 68 & 25 & $3: 1$ & 0,18 & $0,75-0,50$ \\
\hline IAC-24 x Anahuac 75 & $\mathrm{~T} \times \mathrm{S}$ & 88 & 32 & $3: 1$ & 0,18 & $0,75-0,50$ \\
\hline Anahuac 75/IAC-24 & $\mathrm{S} \times \mathrm{T}$ & 189 & 63 & $3: 1$ & 0,00 & 1,00 \\
\hline IAC-287/IAC-24 & $\mathrm{S} \times \mathrm{T}$ & 224 & 64 & $3: 1$ & 1,19 & $0,50-0,25$ \\
\hline Siete Cerros/IAC-24 & $\mathrm{S} \times \mathrm{T}$ & 169 & 56 & $3: 1$ & 0,001 & $0,98-0,95$ \\
\hline IAC-289/IAC-24 & $\mathrm{S} \times \mathrm{T}$ & 75 & 37 & $3: 1$ & 3,86 & $0,05-0,02$ \\
\hline Anahuac 75/IAC-60 & $\mathrm{S} \times \mathrm{T}$ & 84 & 31 & $3: 1$ & 0,24 & $0,75-0,50$ \\
\hline IAC-60/Siete Cerros & $\mathrm{T} \times \mathrm{S}$ & 241 & 79 & $3: 1$ & 0,02 & $0,90-0,75$ \\
\hline IAC-289/IAC-60 & $\mathrm{S} \times \mathrm{T}$ & 94 & 24 & $3: 1$ & 1,15 & $0,50-0,25$ \\
\hline Veery " S "/IAC-60 & $\mathrm{S} \times \mathrm{T}$ & 92 & 25 & $3: 1$ & 0,82 & $0,50-0,25$ \\
\hline Anahuac 75/C-3 & $\mathrm{S} \times \mathrm{T}$ & 229 & 85 & $3: 1$ & 0,72 & $0,50-0,25$ \\
\hline Siete Cerros/C-3 & $\mathrm{S} \times \mathrm{T}$ & 242 & 78 & $3: 1$ & 0,07 & $0,90-0,75$ \\
\hline IAC-287/IAC-5 & $\mathrm{S} \times \mathrm{T}$ & 244 & 76 & $3: 1$ & 0,27 & $0,75-0,50$ \\
\hline IAC-18/Anahuac 75 & $\mathrm{~T} \times \mathrm{S}$ & 78 & 25 & $3: 1$ & 0,03 & $0,90-0,75$ \\
\hline IAC-21/Anahuac 75 & $\mathrm{~T} \times \mathrm{S}$ & 70 & 36 & $3: 1$ & 4,54 & $0,05-0,02$ \\
\hline
\end{tabular}

${ }^{1}$ Probabilidade de sucesso entre as freqüências obtidas e esperadas pela hipótese de segregação de um par de genes. 
vendo cruzamentos entre as cultivares tolerantes e as sensíveis o que indica que as cultivares tolerantes diferiram das sensíveis por um par de genes dominantes para tolerância. Fizeram exceção as populações $\mathrm{F}_{2}$ dos cruzamentos IAC-289 x IAC-24 e IAC-21 x Anahuac 75, que segregaram na proporção de 75 plantas tolerantes para 37 plantas sensíveis e 70 plantas tolerantes para 36 plantas sensíveis, respectivamente, aproximando-se da proporção esperada, de 3:1, com baixo valor de probabilidade. Esse fato poderia ser explicado pela presença de genes modificadores, conforme sugerido por Kerridge \& Kronstad (1968) estudando a herança da tolerância à toxicidade de $\mathrm{Al}^{3+}$ em trigo a partir do cruzamento entre a cultivar tolerante Druchamp e a sensível Brevor.

As populações $\mathrm{F}_{2}$ dos cruzamentos entre cultivares tolerantes mostraram que todas as plantas avaliadas em soluções nutritivas de tratamento contendo $3 \mathrm{mg} / \mathrm{L}$ de $\mathrm{Al}^{3+}$ apresentaram reação de tole- rância (Tabela 3), isto é, apresentaram crescimento radicular em 72 horas de cultivo em soluções nutritivas completas após o tratamento na solução com $\mathrm{Al}^{3+}$. Esses resultados indicam que as cultivares tolerantes não diferiram entre si quanto à presença de par de genes de tolerância à toxicidade de Al.

Tal fato era de se esperar, considerando que a cultivar BH-1146 é originária do cruzamento $\mathrm{PG}_{1} / /$ Fronteira/Mentana e o cruzamento Fronteira/ Mentana deu origem à cultivar Frontana. As cultivares IAC-227 e IAC-18 são provenientes de cruzamentos envolvendo a 'BH-1146'. As cultivares C-3 e C-17 foram obtidas a partir de cruzamentos onde um dos pais era a cultivar Veranópolis, que, por sua vez, originou-se do híbrido Trintecinco/Frontana. As cultivares IAC-74 e IAC-21 foram selecionadas de híbridos onde um dos parentais utilizados foi a cultivar C-17. A cultivar IAC-5 é proveniente do cruzamento: Frontana/Kenya 58// $\mathrm{PG}_{1}$. IAC-60 é originária de híbrido envolvendo IAC-5. A 'IAC-24' provém

TABELA 3. Reações à toxicidade de alumínio $(3 \mathrm{mg} / \mathrm{L})$ em soluções nutritivas de populações híbridas de trigo em geração $F_{2}$, provenientes de cruzamentos entre genótipos tolerantes, expressas em número de plantas tolerantes (T) e número de plantas sensíveis (S) ao alumínio tóxico.

\begin{tabular}{|c|c|c|c|c|c|c|}
\hline \multirow[t]{2}{*}{ Cruzamentos } & \multirow{2}{*}{$\begin{array}{l}\text { Reação } \\
\text { dos } \\
\text { parentais }\end{array}$} & \multicolumn{2}{|c|}{ Número de plantas } & \multirow{2}{*}{$\begin{array}{c}\text { Proporção } \\
\text { esperada } \\
\text { T : S }\end{array}$} & \multirow[t]{2}{*}{$\chi^{2}$} & \multirow[t]{2}{*}{ Probabilidade $^{1}$} \\
\hline & & $\mathrm{T}$ & $\mathrm{S}$ & & & \\
\hline BH-1146/IAC-227 & $\mathrm{T} \times \mathrm{T}$ & 320 & 0 & $1: 0$ & 0 & 1,00 \\
\hline BH-1146/IAC-24 & $\mathrm{T} \times \mathrm{T}$ & 318 & 0 & $1: 0$ & 0 & 1,00 \\
\hline IAC-24/BH-1146 & $\mathrm{T} \times \mathrm{T}$ & 320 & 0 & $1: 0$ & 0 & 1,00 \\
\hline IAC-60/BH-1146 & $\mathrm{T} \times \mathrm{T}$ & 160 & 0 & $1: 0$ & 0 & 1,00 \\
\hline BH-1146/C-3 & $\mathrm{T} \times \mathrm{T}$ & 313 & 0 & $1: 0$ & 0 & 1,00 \\
\hline BH-1146/IAC-5 & $\mathrm{T} \times \mathrm{T}$ & 199 & 0 & $1: 0$ & 0 & 1,00 \\
\hline BH-1146/IAC-21 & $\mathrm{T} \times \mathrm{T}$ & 320 & 0 & $1: 0$ & 0 & 1,00 \\
\hline BH-146/C-17 & $\mathrm{T} \times \mathrm{T}$ & 280 & 0 & $1: 0$ & 0 & 1,00 \\
\hline C-17/BH-1146 & $\mathrm{T} \times \mathrm{T}$ & 299 & 0 & $1: 0$ & 0 & 1,00 \\
\hline BH-1146/IAC-74 & $\mathrm{T} \times \mathrm{T}$ & 313 & 0 & $1: 0$ & 0 & 1,00 \\
\hline IAC-227/IAC-24 & $\mathrm{T} \times \mathrm{T}$ & 320 & 0 & $1: 0$ & 0 & 1,00 \\
\hline C-17/IAC-227 & $\mathrm{T} \times \mathrm{T}$ & 320 & 0 & $1: 0$ & 0 & 1,00 \\
\hline IAC-60/C-3 & $\mathrm{T} \times \mathrm{T}$ & 160 & 0 & $1: 0$ & 0 & 1,00 \\
\hline C-17/IAC-21 & $\mathrm{T} \times \mathrm{T}$ & 160 & 0 & $1: 0$ & 0 & 1,00 \\
\hline C-17/IAC-18 & $\mathrm{T} \times \mathrm{T}$ & 160 & 0 & $1: 0$ & 0 & 1,00 \\
\hline C-17/IAC-5 & $\mathrm{T} \times \mathrm{T}$ & 317 & 0 & $1: 0$ & 0 & 1,00 \\
\hline C-17/IAC-74 & $\mathrm{T} \times \mathrm{T}$ & 292 & 0 & $1: 0$ & 0 & 1,00 \\
\hline IAC-74/C-3 & $\mathrm{T} \times \mathrm{T}$ & 194 & 0 & $1: 0$ & 0 & 1,00 \\
\hline
\end{tabular}

${ }^{1}$ Probabilidade de sucesso entre as freqüências obtidas e esperadas pela hipótese de segregação de um par de genes. 
da cultivar IAS-51 de genealogia desconhecida, porém há grande possibilidade de que esta última também seja originária de Frontana ou de alguma cultivar que tenha germoplasma desta.

Essas informações, juntamente com os resultados obtidos, demonstram que a base genética das cultivares empregadas como fontes de tolerância à toxicidade de $\mathrm{Al}^{3+}$ em cruzamentos é bastante estreita.

O par de genes dominantes em relação à tolerância à toxicidade de $\mathrm{Al}$, identificado na cultivar BH-1146 (Camargo, 1981) e localizado no cromossoma 4D (Lagos et al., 1991), deve ser o mesmo presente nas demais cultivares avaliadas em soluções nutritivas contendo $3 \mathrm{mg} / \mathrm{L} \mathrm{Al}^{3+}$, por meio de cruzamentos envolvendo cultivares tolerantes e também considerando os cruzamentos entre tolerantes e sensíveis.

\section{CONCLUSÕES}

1. O caráter tolerância à toxicidade a $3 \mathrm{mg} / \mathrm{L} \mathrm{de}$ $\mathrm{Al}^{3+}$ em soluções nutritivas é dominante em todos os cruzamentos estudados envolvendo as cultivares tolerantes e sensíveis.

2. As cultivares tolerantes diferem das sensíveis por um par de genes, considerando-se 24 dos cruzamentos avaliados.

3. Não há diferença entre as cultivares tolerantes em relação ao par de genes dominantes em relação à tolerância à presença de $3 \mathrm{mg} / \mathrm{L}$ de $\mathrm{Al}^{3+}$ nas soluções nutritivas.

4. Qualquer uma dessas cultivares pode ser utilizada como fonte de tolerância num programa de cruzamentos onde essa característica for desejada.

\section{REFERÊNCIAS}

ANIOL, A. Introduction of aluminum tolerance into aluminum sensitive wheat cultivars. Plant Breeding, Berlin, v.93, p.331-339, 1984.

BONA, L.; CARVER, B.F.; WRIGHT, R.J.; BALIGAR, V.C. Aluminum tolerance of segregating wheat populations in acid soil and nutrient solutions. Communications in Soil Science and Plant Analysis, New York, v.25, p.327-338, 1994.

CAMARGO, C.E. de O. Melhoramento do trigo. I. Hereditariedade da tolerância ao alumínio tóxico. Bragantia, Campinas, v.40, p.33-45, 1981.
CAMARGO, C.E. de O. Melhoramento do trigo. VI. Hereditariedade da tolerância a três concentrações de alumínio em solução nutritiva. Bragantia, Campinas, v.43, n.2, p.279-291, 1984.

CAMARGO, C.E. de O. Trigo. In: FURLANI, A.M.C.; VIEGAS, G.P. (Eds.). O melhoramento de plantas no Instituto Agronômico de Campinas. Campinas : Instituto Agronômico, 1993. p.431-488.

CAMARGO, C.E. de O.; FELICIO, J.C.; FERREIRA FILHO, A.W.P. Variedades de trigo para o Estado de São Paulo. Campinas : Instituto Agronômico, 1996. 20p. (Boletim Técnico, 163).

CAMARGO, C.E. de O.; OLIVEIRA, O.F. de. Tolerância de cultivares de trigo a diferentes níveis de alumínio em solução nutritiva e no solo. Bragantia, Campinas, v.40, p.21-31, 1981.

CAMPBELL, L.G.; LAFEVER, H.N. Heritability of aluminum tolerance in wheat. Cereal Research Communications, Szeged, v.9, p.281-287, 1981.

FELICIO, J.C.; CAMARGO, C.E. de O.; FERREIRA FILHO, A.W.P.; RAMOS, V.J.; VITTI, P. IAC-60 Centenário e IAC-162 Tuiuiu: cultivares de trigo para sequeiro e irrigado no Estado de São Paulo. Bragantia, Campinas, v.50, n.2, p.291-307, 1991.

FELICIO, J.C.; CAMARGO, C.E. de O.; VITTI, P.; PEREIRA, J.C.V.N.A. Origem e avaliação de trigo Tapajós (IAC-72), Anhumas (IAC-227) e Yaco (IAC-287) para o Estado de São Paulo. Bragantia, Campinas, v.52, n.2, p.219-235, 1994.

KERRIDGE, P.C. Aluminum toxicity in wheat (Triticum aestivum Vill., Host ). Corvallis : Oregon State University, 1969. 170p. Ph.D. Thesis.

KERRIDGE, P.C.; KRONSTAD, W.E. Evidence of genetic resistance to aluminum toxicity in wheat ( Triticum aestivum Vill., Host ). Agronomy Journal, Madison, v.60, p.710-711, 1968.

LAGOS, M.B.; FERNANDES, M.I.B. de M.; CAMARGO, C.E. de O.; FEDERIZZI, L.C.; CARVALHO, F.I.F. de. Genetics and monossomic analysis of aluminum tolerance in wheat (Triticum aestivum L.). Revista Brasileira de Genética, Ribeirão Preto, v.14, n.4, p.1011-1020, 1991.

MOORE, D.P.; KRONSTAD, W.E.; METZGER, R.J. Screening wheat for aluminum tolerance. In: WORKSHOP ON PLANT ADAPTATION TO MINERAL STRESS IN PROBLEM SOILS, 1976, Beltsville. Proceedings. Ithaca : Cornell University, 1976. p.287-295. 